\title{
Risk Factors Associated with Meconium-Stained Amniotic Fluid in Neonates: A Tertiary Centre Experience from Bangladesh
}

\author{
Rafia Rashid $^{1 *}$, Md. Abid Hossain Mollah ${ }^{2}$, Manisha Banerjee ${ }^{3}$, Syed Shafi Ahmed ${ }^{1}$, Salahuddin Mahmud ${ }^{1}$ and \\ Nahid-E-Subha ${ }^{4}$ \\ ${ }^{1}$ Department of Paediatric Gastroenterology, Hepatology \& Nutrition, Dhaka Shishu (Children) Hospital, Dhaka, Bangladesh \\ ${ }^{2}$ Department of Neonatology, BIRDEM General Hospital, Dhaka, Bangladesh \\ ${ }^{3}$ Department of Neonatology, Dhaka Medical College Hospital, Dhaka, Bangladesh \\ ${ }^{4}$ Director General of Health Services, Dhaka, Bangladesh
}

Submission: March 24, 2021; Published: April 01, 2021

*Corresponding author: Dr. Rafia Rashid, Postal address: 1/B Central Road, Dhanmondi, Dhaka 1205, Bangladesh, Tel: +8801819420570

Abstract

Objectives: This study evaluates the risk factors associated with meconium-stained amniotic fluid in neonates managed in the special care baby unit of Dhaka Medical College Hospital (DMCH).

Methods: This case-control study was performed in DMCH from 1st March to 31st December 2011. One hundred fifty-two neonates were selected purposively. Seventy-six cases with meconium staining at birth formed the case group, and other seventy-six cases without meconium staining formed the control group. For both the case and control groups, information about the duration of labour, mode of delivery, maternal illness, and maternal medication during pregnancy were recorded. Any other complications like obstructed labour, history of premature rupture of membrane (PROM), and history of less fetal movement were taken from parents and available medical records. This data was then processed and analyzed using SPSS (version 24) to identify the newborn's risk factors associated with meconium staining. The odds ratio was calculated to identify the risk factors of meconium staining. Parents and guardians of the enrolled neonates were informed about the study, and written consent was obtained. The Ethical Review Committee of Dhaka Medical College Hospital approved this study.

Results: Among the 152 neonates, all the 76 neonates of the case group had meconium staining at birth, and the rest 76 neonates of the control group did not have meconium staining. In the case group, $17.1 \%$ neonates had only staining, $73.7 \%$ neonates had ingestion, and $9.2 \%$ neonates had features of aspiration. $65.8 \%$ of study patients of the case group had fetal distress at birth, whereas only $3.9 \%$ of the control group had fetal distress. Out of the total 152 neonates, only 18 had gestational age more than 42 weeks, of which 13 neonates had meconium staining at birth. Delivery mode lower uterine Caesarean section (LUCS) was more common in the case (77.6\%) group than the control (46.1\%) group. In the case group, $86.8 \%$ of neonates had a prolonged duration of labour. Obstructed labour, presence of PROM, maternal illness, and maternal age had no statistically significant association with meconium staining. 99 out of 152 neonates required hospitalization for $72-96$ hours. Only 8 cases had expired; among them, 5 cases had ingestion and 3 cases had aspiration.

Conclusion: This study found that fetal distress, gestational age of baby, delivery by LUCS, and prolonged duration of labour were significant risk factors of meconium staining at birth.

Keywords: Meconium-stained amniotic fluid, Meconium aspiration syndrome, Risk factors

\section{Introduction}

The presence of meconium in amniotic fluid is a potentially serious sign of fetal compromise mortality and morbidities [1,2]. It has been associated with poor perinatal outcomes, including low APGAR scores, increased rate of chorioamnionitis, increased incidence of neonatal intensive care admission, and a high perinatal death rate [3].

Meconium passage is rare before 34 weeks of gestations, and after 37 weeks, its incidence increases steadily with increasing 
gestational age [4]. Passage of meconium in utero with staining of the amniotic fluid occurs $12 \%$ to $16 \%$ of all deliveries [5-7]. The presence of meconium below the vocal cord is known as meconium aspiration. It occurs in $20 \%$ to $30 \%$ of all infants with meconium-stained amniotic fluid [8], with around $12 \%$ mortality [6]. Aspiration can occur in utero with fetal gasping or after birth with the first breaths of life [9].

Meconium aspiration syndrome (MAS) occurs at higher rates in pregnancies beyond 40 weeks, with $34 \%$ of cases born after 40 weeks. In a study in 1996, among 1426 deliveries, 204 deliveries had MSAF, of which thick meconium was present in 141 [10]. From August 1999 to July 2000, in another study, the total number of live births was 3002, and the incidence of meconium-stained amniotic fluid was $8.3 \%(249 / 3002)$ [11].

MSAF is associated with lots of adverse outcomes of the fetus and has long been considered a bad predictor of fetal outcome. There is no significant data regarding the risk factors of meconium staining available for our country. So, this case-control study evaluates the risk factors associated with meconium-stained amniotic fluid in neonates.

\section{Methods}

This case-control study was performed in DMCH from 1st March to 31st December 2011. One hundred fifty-two neonates were selected purposively for the study, excluding sick neonates with birth injuries, congenital anomalies, and multiple gestations. Seventy-six cases with meconium staining at birth formed the case group, and other seventy-six cases without meconium staining formed the control group. For both the case and control groups, information about the duration of labour, mode of delivery, and maternal medication during pregnancy were recorded. The presence of maternal illness such as Gestational Diabetes Mellitus (GDM), pregnancy-induced hypertension (HTN), anaemia, jaundice was also recorded. Any other complications like obstructed labour, history of premature rupture of membrane (PROM), and history of less fetal movement were taken from parents and available medical records. A predefined questionnaire was used to collect data that was then processed and analyzed using the statistical software SPSS (version 24.0). In addition to descriptive statistics, the odds ratio was calculated to identify the risk factors associated with meconium staining of the neonates. Parents and guardians of the enrolled neonates were informed about the study, and written consent was obtained. The Ethical Review Committee of Dhaka Medical College Hospital approved this study.

\section{Results}

A total of 152 neonates were enrolled for the study. All the 76 neonates of the case group had meconium staining at birth. The rest 76 neonates of the control group did not have meconium staining Figure 1.

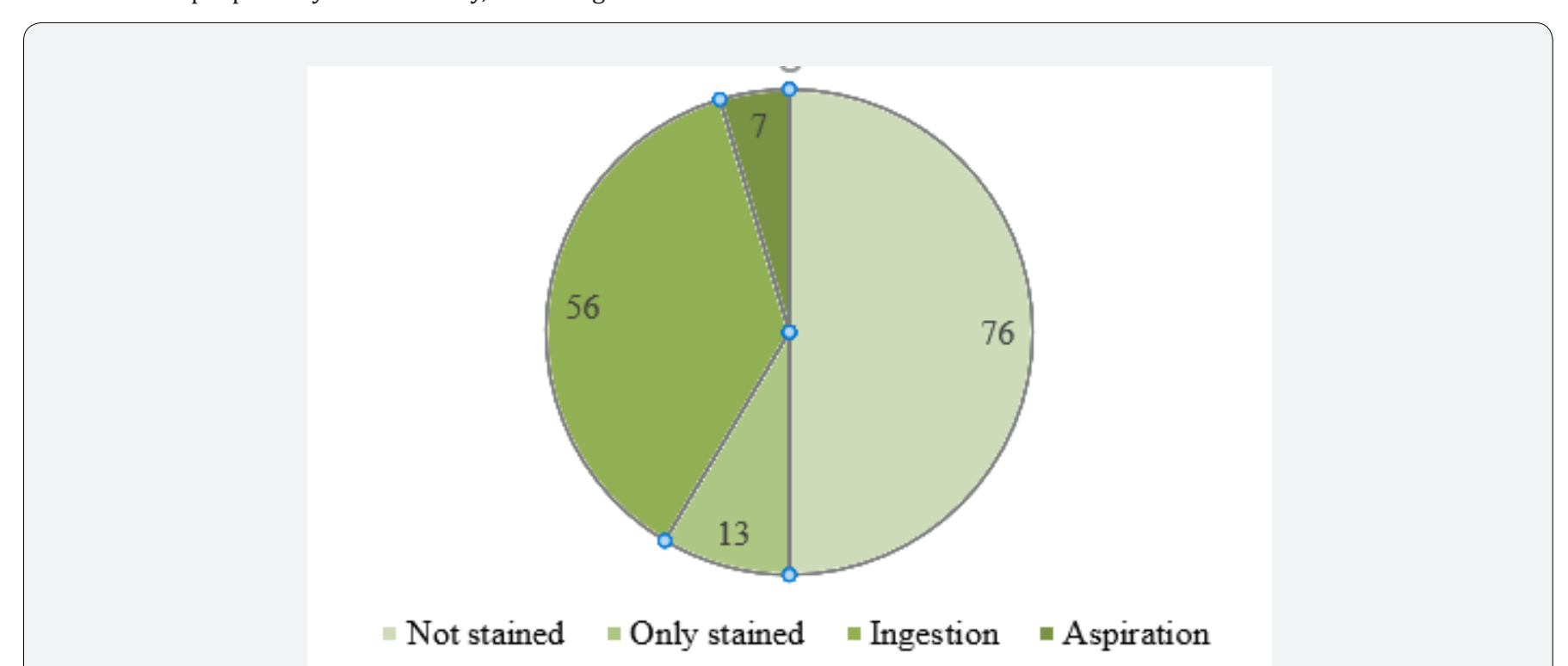

Figure 1: Meconium condition of the studied patients $(n=152)$.

In the case group, $13(17.1 \%)$ neonates had only staining (on the skin, umbilicus, nail), 56 (73.7\%) neonates had staining with ingestion, and the remaining 7 (9.2\%) neonates had features of aspiration along with staining Table 1.
The gestational age of the majority of the studied patients was between 37 to 42 weeks. The average birth weight was 2.649 $( \pm 0.353) \mathrm{kg}$. About $55.3 \%$ of cases were male, and the rest were female Table 2. 
Table 1: Demographic characteristics of the studied patients $(n=152)$.

\begin{tabular}{|c|c|c|}
\hline \multicolumn{2}{|c|}{ Demographic Characteristics } & Number (\%) \\
\hline \multirow{2}{*}{ Gestational age } & $<37$ weeks & $95(25.7 \%)$ \\
\cline { 2 - 3 } & $37-42$ weeks & $18(11.8 \%)$ \\
\cline { 2 - 3 } & $>42$ weeks & $2.649( \pm 0.353)$ \\
\hline \multirow{2}{*}{ Birth weight (kg) } & & (Mean \pm SD) \\
\cline { 2 - 3 } & Male & $84(55.3 \%)$ \\
\hline \multirow{2}{*}{ Gender } & Female & $68(44.7 \%)$ \\
\hline
\end{tabular}

Table 2: Risk factors of the studied patients $(n=152)$.

\begin{tabular}{|c|c|c|c|c|c|}
\hline \multirow[b]{2}{*}{ Risk Factors } & & \multicolumn{2}{|c|}{ Meconium Condition } & \multirow[b]{2}{*}{ Odds Ratio } & \multirow[b]{2}{*}{ P-value } \\
\hline & & $\begin{array}{c}\text { Present } \\
(n=76) \\
n(\%)\end{array}$ & $\begin{array}{c}\text { Absent } \\
(\mathrm{n}=76) \\
\mathrm{n}(\%)\end{array}$ & & \\
\hline \multirow[b]{2}{*}{ Fetal Distress } & Present & $50(65.8 \%)$ & $3(3.9 \%)$ & \multirow[b]{2}{*}{46.79} & \multirow[b]{2}{*}{$<0.001^{*}$} \\
\hline & Absent & $26(34.2 \%)$ & $73(96.1 \%)$ & & \\
\hline \multirow[b]{2}{*}{ Gestational Age } & $>42$ weeks & $13(17.1 \%)$ & $5(6.6 \%)$ & \multirow[b]{2}{*}{2.93} & \multirow[b]{2}{*}{$0.045^{*}$} \\
\hline & $\leq 42$ weeks & $63(82.9 \%)$ & $71(93.4 \%)$ & & \\
\hline \multirow{2}{*}{ Mode of Delivery } & Lower uterine Caesarean section (LUCS) & $59(77.6 \%)$ & $35(46.1 \%)$ & \multirow{2}{*}{4.07} & \multirow{2}{*}{$<0.001^{*}$} \\
\hline & Normal vaginal delivery (NVD) & $17(22.4 \%)$ & $41(53.9 \%)$ & & \\
\hline \multirow[b]{2}{*}{ Prolonged Labour } & Yes & $66(86.8 \%)$ & $46(60.5 \%)$ & \multirow[b]{2}{*}{4.3} & \multirow[b]{2}{*}{$<0.001^{*}$} \\
\hline & No & $10(13.2 \%)$ & $30(39.5 \%)$ & & \\
\hline \multirow{2}{*}{ Obstructed Labour } & Yes & $9(11.8 \%)$ & $6(7.9 \%)$ & \multirow{2}{*}{1.57} & \multirow{2}{*}{0.415} \\
\hline & No & $67(88.2 \%)$ & $70(92.1 \%)$ & & \\
\hline \multirow[b]{2}{*}{ History of PROM } & Present & $22(28.9 \%)$ & $19(25.0 \%)$ & \multirow[b]{2}{*}{1.22} & \multirow[b]{2}{*}{0.584} \\
\hline & Absent & $54(71.1 \%)$ & $57(75.0 \%)$ & & \\
\hline \multirow[b]{2}{*}{ Maternal Illness } & Present & $31(40.8 \%)$ & 25 (32.9\%) & \multirow[b]{2}{*}{1.41} & \multirow[b]{2}{*}{0.313} \\
\hline & Absent & $45(59.2 \%)$ & $51(67.1 \%)$ & & \\
\hline \multirow[b]{2}{*}{ Maternal Age } & $>30$ years & $6(7.9 \%)$ & $4(5.3 \%)$ & \multirow[b]{2}{*}{1.54} & \multirow[b]{2}{*}{0.513} \\
\hline & $\leq 30$ years & $70(92.1 \%)$ & $72(94.7 \%)$ & & \\
\hline
\end{tabular}

\section{* Statistically significant}

$65.8 \%$ of study patients of the case group had fetal distress at birth, whereas only $3.9 \%$ of the control group had fetal distress. In the control group, the majority of the studied neonates had no fetal distress. Out of the total 152 neonates, only 18 had gestational age more than 42 weeks, of which 13 neonates had meconium staining at birth. Delivery mode LUCS was more common in the case $(77.6 \%)$ group than the control $(46.1 \%)$ group. In the case group, $86.8 \%$ of neonates had a prolonged duration of labour. 
$60.5 \%$ of neonates from the control group had prolonged labour. The majority of the neonates from both the case and control groups had no history of obstructed labour. Similarly, the history of PROM was not present in most cases from both groups. There was no statistically significant association between the presence of any maternal illness (GDM, HTN, jaundice, and others) with meconium staining. Only 6.6\% (10 out of 152) of mothers had an age more than 30 years.

Sixty-five percent (99 out of 152) neonates required one or more forms of resuscitation at birth. All these cases were hospitalized for 72 - 96 hours on average. Only eight cases had expired; among them, 5 cases had staining with ingestion, and 3 cases had staining with aspiration.

\section{Discussion}

The present study findings were compared with previously published relevant studies regarding the risk factors associated with the presence of meconium. In this current study, it was observed that other demographic characteristics like gender and birth weight of the babies did not significantly affect meconium staining.

This study found that fetal distress is a statistically significant risk factor of MSAF with a very high odds ratio of 46.79. Among the study neonates, $65.8 \%$ of the case group had fetal distress at birth compared to only $3.9 \%$ in the control group. Thirty-five percent of all the study neonates had fetal distress. Shukla and Swapna also reported $23.7 \%$ of cases with the MSAF having fetal distress [12]. Mohammad et al. [13] found that mechanical stress on the fetus was predominantly associated with thick meconium.

Prolonged duration of labour is also a risk factor for the passage of meconium in utero, as proved by Saunder et al. [14]. They showed in their study that prolonged labour is associated with the worst outcome in the MSAF group. According to the current study, prolonged duration of labour is a risk factor of MSAF with an odds ratio of 4.3. Among the study neonates, $86.8 \%$ of the case and $60.5 \%$ of the control group experienced prolonged labour. 35 out of 56 cases of ingestion and 4 out of 7 cases of aspiration had a labour of more than 24 hours.

In agreement with the previous work of Khatun et al. [15], this current study revealed that delivery by LUCS significantly influenced the presence of MSAF at birth with an odds ratio of 4.07. Sixty-two percent of the 152 neonates had delivery by LUCS; among them 59 from the case group and 35 from the control group. Erum et al. [16] found that among 250 women with meconium-stained amniotic fluid, 205 women delivered by caesarean section, and 45 women had a normal vaginal delivery. Chaudhary et al. showed that 45 patients (54.2\%) delivered by LUCS and 38 (45.7\%) babies were delivered by vaginal delivery [17], which is also close to our study.

Sunoo et al. [18] found a significantly increased rate of meconium in amniotic fluid at 39 weeks. In this study, it was also found that the rate of MSAF was high with increase gestational age of babies. The majority of the ingestion and aspiration cases were found for gestational ages greater than 37 weeks. Specifically, 42 out of 56 cases of ingestion and all the 7 cases of aspiration had a gestational age greater than 37 weeks. This study also found that gestational age of more than 42 weeks is a significant factor of MSAF with an odds ratio of 2.93. Chhetri and Aryal [19] found that $64 \%$ of mothers with MSAF were between $41-42$ weeks of gestation. Chaudhary R et al., reported that $59 \%$ of mothers with MSAF were of 38-40 weeks of gestation [17].

In this study, we also evaluated the presence of obstructed labour, PROM, and maternal illness as potential risk factors for MSAF. However, we did not find any statistically significant association between these factors and MSAF at birth.

Sankhyan et al. [20] identified maternal age $>30$ years, fetal distress, and postdated pregnancies are predictors of thick MSAF. Chaudhary R et al. [17] also found that maternal risk factors for MSAF in decreasing frequency were maternal age $<25$ years. This current study did not find any significant association between maternal age and MSAF.

\section{Conclusion}

This study found that fetal distress, gestational age of baby, delivery by LUCS and prolonged duration of labour were significant risk factors of meconium staining at birth. Identifying these risk factors may help in early detection of complications and management of meconium-stained neonates.

\section{Source of Funding}

The authors did not receive any grant for this research study.

\section{Conflicts of Interest}

We, the authors declare that we have no conflicting interests.

\section{Acknowledgment}

We want to thank all the faculties, fellowship students, residents, and staff of the Department of Neonatology, Dhaka Medical College Hospital and the Department of Paediatric Gastroenterology, Hepatology \& Nutrition, Dhaka Shishu (Children) Hospital, for their technical and administrative assistance. We also want to thank all the parents of our patients who were very cooperative throughout the study period.

\section{References}

1. Berkus MD, Langer O, Samuelloff A, Zenakis EM, Field NT, et al. (1994) Meconium stained amniotic fluid: Increased risk for adverse neonatal outcome. Obstet Gynecol 84(1): 115-120.

2. Nathan L, Lenevo KJ, Camody TJ III, Kelly MA, Sherman ML (1994) Meconium: a 1990s perspective on an obstetric hazard. Obstet Gynecol 83(3): 329-332. 
3. Ahanya SN, Lakshmanan J, Morgan BL, Ross MG (2005) Meconium passage in utero: mechanisms, consequences, and management. Obstet Gynecol Surv 60(1): 45-56.

4. Wiswell TE, Henley MA (1992) Intratracheal suctioning, systemic infection and the meconium aspiration syndrome. Pediatrics 89(2): 203-206.

5. Cleary GM, Wiswell TE (1998) Meconium-stained amniotic fluid and the meconium aspiration syndrome. An update. Pediatr Clin North Am 45(3): 511-529.

6. Maymon E, Chaim W, Furman B, Ghezzi F, ShohamVardi I, et al. (1998) Meconium stained amniotic fluid in very low risk pregnancies at term gestation. Eur J Obstet Gynecol Reprod Biol 80(2): 169-173.

7. Wiswell TE, Bent RC (1993) Meconium staining and the meconium aspiration syndrome. Unresolved issues. Pediatr Clin North Am 40(5): 955-981.

8. Kligner MC, Kruse J (1999) Meconium aspiration syndrome: Pathophysiology and prevention. J Am Board Fam Pract 12(6): 450466.

9. Romero R, Hanaoka S, Mazor M, Athanassiadis AP, Callahan R, et al (1991) Meconium-stained amniotic fluid: a risk factor for microbial invasion of the amniotic cavity. Am J of Obstet Gynecol 164(3): 859862

10. Gupta V, Bhatia BD, Mishra OP (1996) Meconium stained amniotic fluid: antenatal, intrapartum and neonatal attributes. Indian Pediatrics 33(4): 293-297.

11. Patil KP, Swamy MK, Samatha K (2006) A one year cross sectional study of management practices of meconium stained amniotic fluid and perinatal outcome. Obstet Gynecol India 56: 128-130.
12. Shukla OS, Swapna ST (2019) Study of risk factors, clinical profile, and outcome in meconium-stained deliveries. Indian J Child Health 6(5): 213-216.

13. Mohammad N, Jamal T, Sohaila A, Ali SR (2018) Meconium stained liquor and its neonatal outcome. Pak J Med Sci 34(6):1392-1396.

14. Saunders K (2002) Should be worry about meconium? A controlled study of neonatal outcome. Trop Doct 32(1): 7-10.

15. Khatun M (2005) Meconium Staining liquor and its correlative with fetal outcome within seven days of birth in Dhaka Medical College. Dissertation. Bangladesh College of Physicians and Surgeons 2005: 3943.

16. Erum MS, Sadaf M, Majid AS (2010) Neonatal outcome in meconium stained amniotic fluid-one year experience. J Pak Med Assoc 60(9): 711.

17. Chaudhary R, Sethi RS, Chaurasiya OS, Sethi AS (2018) Study of meconium aspiration syndrome in relation to birth weight and gestational age. Peoples J Sci Res 11: 16-21.

18. Sunoo CS, Kosasa TB, Nakayama RT, Hale RW (1993) The incidence of meconium aspiration in Hawaii. Hawaii Med J 52: 290-293.

19. Chhetri UD, Aryal S (2020) Risk Factors and Perinatal Outcome of Meconium Stained Amniotic Fluid. Journal of Lumbini Medical College 8(1): 77-82.

20. Sankhyan N, Sharma VK, Sarin R, Pathania K (2006) Predictors of meconium stained amniotic fluid: a possible strategy to reduce neonatal morbidity and mortality. J Obstet Gynecol India 56(6): 514517.

\begin{tabular}{|l|}
\hline \multicolumn{1}{|c|}{ Your next submission with Juniper Publishers } \\
will reach you the below assets \\
- Quality Editorial service \\
- Swift Peer Review \\
- Reprints availability \\
- E-prints Service \\
- Manuscript Podcast for convenient understanding \\
- Global attainment for your research \\
- Manuscript accessibility in different formats \\
( Pdf, E-pub, Full Text, Audio) \\
- Unceasing customer service \\
Track the below URL for one-step submission \\
https://juniperpublishers.com/online-submission.php
\end{tabular}

